\title{
APONTAMENTOS SOBRE A REGULAÇÃO ESTATAL DOS PREÇOS PRIVADOS NO CONTEXTO DA PANDEMIA DA COVID-19
}

\author{
Leonardo de Andrade Costa $^{1}$
}

\section{Resumo:}

O presente ensaio acadêmico objetiva analisar os contornos jurídicos dos principais instrumentos regulatórios e limites da interveniência estatal sobre a liberdade dos agentes econômicos estabelecerem os preços privados no Brasil, a partir do contexto desenhado pela pandemia da Covid-19, no qual foi possível constatar abrupto aumento da demanda de alguns produtos utilizados para prevenção da doença, além de incremento pontual e transitório do poder de compra da parcela mais pobre da população, especialmente em relação aos alimentos, em razão do auxílio emergencial, e do crescimento do volume de transações comerciais realizadas por meio da internet no mesmo período.

Palavras-chave: regulação; preços privados; liberdade econômica; intervenção estatal

\section{NOTES ON STATE REGULATION OF PRIVATE PRICES IN THE CONTEXT OF THE COVID-19 PANDEMIC}

\begin{abstract}
:
This academic essay aims to analyze the legal regulatory instruments and limits of state intervention on the freedom of economic agents to establish private prices in Brazil, from the context designed by the Covid-19 pandemic, in which it was possible to observe an abrupt increase in the demand of some products used to prevent the disease, in addition to a punctual and transitory increase in the purchasing power of the poorest population, especially in relation to food, due to emergency aid, and the growth in the volume of commercial transactions carried out through the Internet in the same period.
\end{abstract}

Keywords: regulation; private prices; economic freedom; state intervention

\section{INTRODUÇÃO}

O ano de 2020 e o início de 2021 serão, indubitavelmente, sempre lembrados pelas fatalidades ocorridas em razão da pandemia da Covid-19 - trata-se de uma doença infecciosa causada pelo coronavírus SARS-COV-2 (WHO, 2021), e, por conseguinte, dos seus impactos na vida das pessoas e nas economias dos países em geral, trazendo a reboque crises institucionais.

No Brasil, onde o grau de extrema pobreza chega ao patamar de $6,5 \%$ da população, segundo estudos do Síntese de Indicadores Sociais de 2019 (Agência IBGE, 2021), a referida pandemia impactou a economia de forma substantiva. As consequências foram significativas no que alude ao ritmo da atividade econômica, tendo o Produto Interno Bruto (PIB) caído

\footnotetext{
${ }^{1}$ Doutorando em direito da regulação e professor da graduação da FGV Direito Rio. Mestre em Direito Econômico e Financeiro pela Universidade de São Paulo (USP)/ Harvard Law School, Cambridge, MA.
} 
9,7\% no segundo trimestre de 2020 (comparado ao primeiro trimestre de 2020), na série com ajuste sazonal, e, em relação a igual período de 2019 , sofreu retração de $11,4 \%$. O impacto também foi incisivo no que se refere aos preços de bens essenciais, como alimentos (o arroz e feijão chegaram a subir 69,5\%), itens de higiene e produtos utilizados para prevenção da doença, a exemplo do álcool gel, luvas e máscaras, cujo acréscimo da demanda foi abrupto e contundente, sem que houvesse prévia adequação da estrutura da oferta (ECONOMIA IG, 2021).

Além do aumento substancial do nível de desemprego, que já era alto, o que deu ensejo à concessão do chamado auxílio emergencial, em adição aos benefícios sociais já existentes, a pandemia, decorrente da disseminação da Covid-19, também impulsionou as interações virtuais, especialmente as compras realizadas por meio da internet, ligando fornecedores e consumidores virtualmente. Estudos revelam, por exemplo, que o consumo virtual da chamada camada $C$ da população no Brasil subiu de $37 \%$ para $64 \%$ em $2020 \mathrm{com}$ a deflagração da pandemia (CONVERGÊNCIA DIGITAL, 2021).

Nesse cenário, especialmente em face do disposto no Código de Defesa do Consumidor (CDC), instituído pela Lei $\mathrm{n}^{\circ}$ 8.078/1990, e do Sistema Brasileiro de Defesa da Concorrência (SBDC), instituído pela Lei $\mathrm{n}^{\circ}$ 12.529/2011, dois aspectos sobre o consumo chamam a atenção sob a perspectiva dos instrumentos regulatórios existentes no país e, bem assim, da governança institucional.

O primeiro aspecto diz respeito aos efeitos ocasionados pelo aumento do consumo e elevação dos preços dos alimentos básicos, especialmente do arroz, o que ensejou noticiado conflito entre o Ministério da Economia e o Ministério da Justiça, quanto à viabilidade, adequação e consequências do controle dos preços do produto realizado pela Secretaria Nacional do Consumidor (Metrópoles.com, 2020).

O segundo refere-se aos limites da interferência estatal no que alude aos critérios utilizados pelo mercado para fixar preços diferenciados com base nas especificidades das transações, características, atributos ou localização dos consumidores (geopricing). No tocante à concepção de geopricing (ou geolocation), trata-se de uma situação na qual o fornecedor precifica a mercadoria ou serviço de forma distinta dependendo da localização do consumidor, sem que o fator de discriminação tenha correlação com os custos empresariais (SAMPAIO, COSTA, 2020).

Vale realçar que o ponto em comum entre desses dois aspectos (efeitos ocasionados pelo aumento do consumo e elevação dos preços dos alimentos básicos e limites da interferência estatal no que alude aos critérios utilizados pelo mercado para fixar preços diferenciados com base nas especificidades das transações, características, atributos ou localização dos consumidores) é que ambos suscitam a análise quanto à possibilidade e conveniência de imposição de limites à liberdade privada de fixar preços, seja quanto ao valor, seja quanto aos critérios utilizados pelo fornecedor para precificação.

A interveniência estatal deve ser cuidadosa, pois não basta a análise quanto à sua possibilidade jurídica, sendo necessário, conjuntamente, examinar elementos de caráter econômico, tendo em vista que o sistema de preços consubstancia mecanismo de comunicação de informação resultante da interação entre a demanda e a oferta nos diferentes mercados, com características e dinâmicas distintas.

Assim, o trabalho visa a apresentar breve exame da juridicidade e adequação dos instrumentos regulatórios disponíveis, além de apontar alguns problemas específicos relacionados à governança institucional no controle de preços no Brasil, o que pode ocorrer por meio de seu acompanhamento e limitação - instrumentos que se diferenciam do tabelamento e do congelamento. Nessa senda, enquanto o tabelamento significa fixação de 
preços máximos, o congelamento, por sua vez, estabelece a manutenção dos preços anteriormente vigentes. Já o controle visa a regular os preços, compatibilizando-os com as variações dos custos, intervindo, portanto, na margem de lucro privada.

Sob o ponto de vista metodológico, adota-se o tipo de pesquisa exploratória, amparada na literatura do tema, em aspectos jurisprudenciais e legais existentes, além da perspectiva econômica acerca do assunto.

\section{O CONTROLE DE PREÇOS PRIVADOS NO BRASIL}

A partir da constatação de que existem vasos comunicantes entre a atuação do "Estado-empresário" e o "Estado-regulador", Alexandre Santos Aragão (2016) apresenta exemplos de intercambialidade entre a atuação direta do Estado na economia e a sua atuação indireta, tanto pela regulação, como pelo fomento.

Ao atuar diretamente na economia, como Estado-empresário, apesar de, em regra, o fim público ser a própria operação econômica que realiza, a relevância do aspecto regulatório pode ser o objetivo principal, concomitante, acessório ou meramente reflexo, conforme salienta Aragão, ao indicar a compra de estoque regulador por parte de estatais como exemplo de atuação direta do Estado na economia com fim eminentemente regulatório. Nesse sentido aponta Aragão:

O principal exemplo dessa modalidade são os estoques reguladores, armazenamentos estatais de bens em circulação no mercado, geralmente alimentos ou combustíveis, com o Estado adquirindo-os quando deseja aumentar ou evitar a queda do seu preço, e alienando-os para impedir a alta do preço do produto ou forçar a sua queda, já que assim se coloca mais bens no mercado, aumentando a sua oferta. Trata-se de atuação direta do Estado (comprador e vendedor de bens) na economia com objetivo regulatório claro, como substituta da regulação jurídica de tabelamento ou de controle de preços, que só se admite para bens de primeira necessidade (Lei Delegada $n^{\circ} 4 / 62$, art. $6^{\circ}$, III e IV), sendo outro instrumento à disposição do Estado para o mesmo objetivo (Revista de Direito Público da Economia, vol. 6, p. 14-15).

Constata-se, portanto, pelo menos dois modos possíveis de atuação estatal para atingir o mesmo objetivo, isto é, regular o preço dos bens de primeira necessidade, o que deve ser realizado com muito cuidado, tendo em vista que a livre inciativa é, ao mesmo tempo, fundamento da República Federativa do Brasil, ao lado dos valores sociais do trabalho, e princípio fundante da ordem econômica.

Importante salientar que a Lei $\mathrm{n}^{\mathrm{o}} 13.874 / 2019$, norma que institui a Declaração de Direitos de Liberdade Econômica e estabelece garantias de livre mercado, revogou a citada Lei Delegada $n^{\circ}$ 4/62, mencionada no texto acima transcrito. Ocorre, no entanto, que o CDC, além de vedar que o fornecedor eleve "sem justa causa o preço de produtos ou serviços", consoante o disposto no inciso $\mathrm{X}$ do art. 39, também prevê, expressamente, em seu art. 41, a possibilidade de controle ou tabelamento de preços, não apenas em relação aos bens de primeira necessidade, nos seguintes termos (Planalto, 2020):

Art. 41. No caso de fornecimento de produtos ou de serviços sujeitos ao regime de controle ou de tabelamento de preços, os fornecedores deverão respeitar os limites oficiais sob pena de não o fazendo, responderem pela restituição da quantia recebida em excesso, monetariamente atualizada, 
podendo o consumidor exigir à sua escolha, o desfazimento do negócio, sem prejuízo de outras sanções cabíveis.

Na mesma linha, a Lei no 12.529/2011, que estrutura o Sistema Brasileiro de Defesa da Concorrência (SBDC) e dispõe sobre a prevenção e repressão às infrações contra a ordem econômica, estabelece no inciso III do seu art. 36, que o aumento arbitrário dos lucros constitui "infração da ordem econômica, independentemente de culpa" (Planalto, 2020).

Por oportuno, como corolário da liberdade econômica, a citada Lei n ${ }^{\circ} 13.874 / 2019$, em seu inciso III, do art. $3^{\circ}$, reafirma o direito, em mercados não regulados, de as pessoas estabelecerem o preço de produtos e de serviços como consequência de alterações da oferta e da demanda. No entanto, prevê, expressamente, que essa prerrogativa não se aplica "à legislação de defesa da concorrência, aos direitos do consumidor e às demais disposições protegidas por lei federal".

Constata-se nesses termos, o reconhecimento de limites à liberdade econômica, além da interconexão entre a prerrogativa de fixar preços, a defesa do consumidor e da concorrência, ainda que não se confundam em seus objetivos, conforme pontua Patrícia Regina Sampaio (2019, p.182). Com efeito, esta interligação faculta desenhos institucionais distintos para gestão dos temas, o que será tangencialmente examinado ao final do texto.

Além dessas disposições de caráter genérico do CDC e do SBDC, é possível identificar outros dispositivos normativos contendo regulação coercitiva sobre preços privados específicos, como, por exemplo, a Lei no 12.933/2013. Esta lei disciplina o benefício do pagamento de meia-entrada para estudantes, idosos, pessoas com deficiência e jovens de 15 a 29 anos, comprovadamente carentes em espetáculos artístico-culturais e esportivos. Com relação a este ato do parlamento federal, vale realçar que não se trata de fomento estatal, pois não há benefício direto conferido pela norma ao empresário que exerce a atividade econômica livre, tampouco há opção de participar ou não da redução dos ingressos. Portanto, trata-se de regulação coercitiva sobre os preços privados, ainda que em área de interesse público, como é o caso da cultura, pois o Estado é obrigado a conceder "acesso às fontes da cultura nacional", a teor do disposto no artigo 215 da CRFB/88.

Por sua vez, a Lei $n^{\circ}$ 9.870/1999 regulamenta o valor das anuidades ou das semestralidades escolares do ensino pré-escolar, fundamental, médio e superior, ao passo que a Lei $n^{\circ} 13.703 / 18$, e a Resolução $n^{\circ} 5.820$ da Agência Nacional de Transportes Terrestres (ANTT), estabelecem preços mínimos para o frete de transporte rodoviário de cargas. A questão relativa aos preços mínimos do frete de transporte rodoviário de cargas previsto pela Lei $\mathrm{n}^{\mathrm{o}}$ 13.703/18, é objeto de discussão nas ADIs 5956, 5959 e 5964. Em 2018, o ministro Luiz Fux, relator do processo, deferiu pedido cautelar suspendendo a aplicação de multas pelo descumprimento dos pisos previstos.

Ainda, com relação a medicamentos, os quais têm valores tabelados pela Câmara de Regulação do Mercado de Medicamentos (CMED), que estabelece critérios para determinar o valor do medicamento, além de divulgar aos consumidores tabela com os preços máximos a serem praticados pelas farmácias. A Medida Provisória no 933/20, de 31.05.2020, suspendeu os reajustes anteriormente previstos pelo prazo de sessenta dias.

Diante desse panorama, é de se indagar como a doutrina e a jurisprudência se posicionam sobre esse tema, isto é, sobre a prerrogativa estatal de intervir sobre a liberdade empresarial de fixar preços privados após a edição da Constituição da República Federativa do Brasil de 1988 (CRFB/88)?

É possível identificar pelo menos três correntes distintas quanto à possibilidade de controle prévio de preços privados no país, após a promulgação da CRFB/88. 
A primeira delas é no sentido de não ser mais possível qualquer tipo de controle estatal prévio de preços, considerando o princípio da livre iniciativa, o qual somente pode ser relativizado no plano constitucional, segundo lições de Diogo de Figueiredo Moreira Neto (1989). De acordo com tal visão, as exceções ao princípio da livre concorrência, após 1988, devem estar expressas no próprio texto constitucional, havendo, atualmente, autorização apenas à repressão de caráter sancionatório, em hipóteses de abuso, mas não de controle preventivo de caráter meramente regulatório, nos termos do art. 173, $4^{\circ}$, CRFB/88.

Em linha diametralmente distinta, antes mesmo da edição do CDC, o Supremo Tribunal Federal (STF) já havia reconhecido a constitucionalidade da fixação de limites legais para mensalidades escolares, na Ação Direta de Inconstitucionalidade (ADI) no 319 (Portal STF, 2020). A Confederação Nacional dos Estabelecimentos de Ensino propôs esta ação em face da Lei $\mathrm{n}^{\circ}$ 8.030/1990 (em tempo: este diploma normativo foi revogado e a matéria encontra-se atualmente disciplinada pela Lei $\mathrm{n}^{\circ}$ 9.870/99), sob o fundamento de que o controle de preços ofendia a livre iniciativa e seus subprincípios, haja vista que o "ensino é livre à iniciativa privada" (art. 209 da CRFB/88), devendo coexistir "instituições públicas e privadas de ensino" (art. 206, III, da CRFB/88).

O relator da ADI em comento, Ministro Moreira Alves, votou pela constitucionalidade da disciplina regulatória, que restringe a liberdade de escolas privadas fixarem livremente os preços cobrados, enfatizando a necessidade de equilibrar o princípio da livre iniciativa com os ditames da justiça social, enumerados nos sete incisos do artigo 170 da CRFB/88. A maioria do plenário do STF acompanhou o voto do relator, e concluiu pela constitucionalidade do controle e limites de preços por razões de interesse público, consideradas legitimadoras da intervenção regulatória estatal na economia.

Até o julgamento da ADI 6445, em 28.05.2021, decisão que será posteriormente examinada, o STF vinha seguido essa mesma linha de pensamento em relação a outros temas, reafirmando a posição, no sentido de que o controle de preços não pressupõe a caracterização de abuso do poder econômico, dominação dos mercados, eliminação da concorrência ou aumento arbitrário de lucro, quando há interesse público envolvido.

Em contraponto, Luís Roberto Barroso, hoje ministro da Suprema Corte, em trabalho acadêmico (Revista de Direito Administrativo, 2001, p.187-212) perfilhou ressalvas à decisão exarada pelo STF na mencionada ADI 319, e indicou modelo intermediário, para propor as circunstâncias que legitimam a atuação estatal no controle prévio de preços privados no país. A partir de dois contextos distintos, define os contornos e limites da regulação estatal relativamente aos preços privados.

O primeiro, na hipótese de política pública regular e de normalidade de funcionamento do mercado, caso no qual, "independentemente dos fundamentos em tese admissíveis para a intervenção disciplinadora, o controle prévio ou a fixação de preços privados pelo Estado configura inconstitucionalidade patente", pois a "Constituição brasileira não admite como política pública regular o controle prévio de preços" (Barroso, 2001, p. 208).

Por outro lado, em caso de "anormalidade do mercado, ausentes as condições regulares de livre concorrência", defende Barroso que "o princípio da livre iniciativa poderá sofrer ponderação para admitir o controle prévio de preços, observados determinados pressupostos" (2001, p. 209). Dessa forma, o jurista fluminense sustenta que não se pode vulnerar o núcleo essencial da livre iniciativa para proteção de um princípio setorial, como é o caso, por exemplo, do direito do consumidor.

Nesses termos, a partir da distinção entre os princípios fundamentais do Estado Brasileiro, como a livre iniciativa e o valor do trabalho humano de um lado, e os princípios 
setoriais de outro, como aqueles ligados ao funcionamento (incisos I a VI do art. 170) ou aos fins da ordem econômica (incisos VII a IX do art. 170), conclui Barroso:

\begin{abstract}
Admite-se, todavia, que em situações anormais seja possível o controle prévio de preços pelo Estado, na medida em que o mercado privado como um todo tenha se deteriorado a ponto de não mais operarem a livre iniciativa e a livre concorrência de forma regular. Nesses casos - excepcionais, repita-se - a intervenção se justifica, afastando o limite material acima referido, exatamente para reconstruir a prática de tais princípios. Isto é: para reordenar o mercado concorrencial de modo que a livre iniciativa e seus corolários possam efetivamente funcionar. Note-se, porém, que o controle prévio de preços só é admissível por esse fundamento. E, mesmo assim, observado o princípio da razoabilidade. Os demais, representados pela valorização do trabalho humano e pelos princípios de funcionamento da ordem econômica, não podem justificar o controle prévio de preços, pois isso seria incompatível com o conteúdo básico da livre iniciativa. Esta proposição é válida, inclusive, em relação à atuação voltada para a proteção do consumidor que é um dos princípios de funcionamento da atividade econômica. E, ademais, também quanto a este ponto, ocorreria o limite imposto pela razoabilidade, haja vista que existem mecanismos menos gravosos para esta proteção - incentivo à concorrência, punição administrativa, civil e penal dos infratores. (grifos não existentes no original) (Revista de Direito Administrativo, 2001, p.187-212).
\end{abstract}

Portanto, de acordo com esta linha de raciocínio, os princípios setoriais, per se, entre eles o da defesa do consumidor, não podem restringir a livre iniciativa, a ponto de afetar seus elementos essenciais, como é o caso da liberdade empresarial de fixar preços privados no país, ressalvadas as circunstâncias excepcionais, hipóteses nas quais devem ser observadas a necessidade, adequação e proporcionalidade em sentido estrito das medidas propostas. Repise-se que a mencionada situação anormal é caracterizada pelo jurista, em razão da impossibilidade de o mercado privado operar sob as condições da livre iniciativa e livre concorrência de forma regular, haja vista a deterioração de seus pressupostos.

No entanto, não basta o exame exclusivamente jurídico do tema, pois somente com a inclusão da perspectiva econômica é revelada a complexidade da matéria e desvelado os requisitos e limites da atuação estatal, tendo em vista que em momentos de pandemia ocorrem choques tanto do lado da oferta como na vertente da demanda por bens e serviços, especialmente em relação a alguns produtos específicos, como é o caso, do álcool gel, luvas e máscaras. Nesses termos, deve-se avaliar, também, a racionalidade econômica da medida regulatória, pois os preços privados são ordinariamente resultantes da interação entre a oferta e a demanda nos mercados onde são negociados os bens e serviços específicos, os quais possuem características variadas. Na linha de preleção de M.A. Vasconcellos e M. E. Garcia (2006, p. 39), o mercado de bens e serviços é usualmente segmentado em: (a) concorrência perfeita; (b) concorrência imperfeita ou monopolista; (c) monopólio; e (d) oligopólio. Por sua vez, o mercado de fatores de produção é classificado como: (a) concorrência perfeita; (b) concorrência imperfeita; (c) monopsônio; e (d) oligopsônio. O mercado pode apresentar, ainda, de modo simultâneo, algumas características de competição e outras de monopólio. Essa estrutura é chamada de competição monopolística.

No mercado de bens e serviços competitivo inexistem barreiras à entrada de novos concorrentes, os produtores e os fornecedores não têm capacidade de estabelecer os seus preços per se, pois cada um é muito pequeno em relação ao mercado como um todo 
("mercado atomizado"), não havendo diferencial significativo entre os produtos oferecidos ("produtos homogêneos"), tampouco poder de influenciar as transações de forma significativa (concorrência perfeita). Caso tentem aumentar os preços além daquele praticado no mercado serão substituídos pelos seus concorrentes, além de não possuírem poder econômico suficiente para praticar preços inferiores àqueles necessários para cobrir os seus custos fixos e variáveis e obter o lucro normal da economia. Nesses termos, os agentes econômicos submetem-se às condições da concorrência livre, sendo o mercado de hortifrutigranjeiros normalmente apontados como exemplo mais próximo da concorrência perfeita (VASCONCELLOS, M. A.; GARCIA, 2006, p. 77).

$\mathrm{Na}$ realidade, este tipo de estrutura representa apenas um parâmetro analítico usualmente utilizado pelos economistas, tendo em vista que as suas hipóteses e premissas são difíceis de serem encontradas ao mesmo tempo no mundo capitalista complexo da atualidade. No entanto, quando não verificada a existência de um único produtor ou fornecedor (monopólio), ou um número pequeno de empresas (oligopólio) que dominem a estrutura de oferta, com poder de mercado suficiente para aplicar uma política própria de precificação, constatam-se, em muitas circunstâncias, os chamados mercados em concorrência monopolística.

Esta estrutura de mercado, como dito, é caracterizada, simultaneamente, pelo elevado número de empresas e a inexistência de barreiras à entrada, o que a aproxima do mercado de concorrência perfeita (além de diferenciá-la do monopólio e do oligopólio), e, ao mesmo tempo, pelo poder relativo que a empresa possui para fixar uma política própria de preços, isto é, uma possibilidade com maiores limitações do que no caso do monopólio, tendo em vista a existência de bens substitutos próximos. Dessa forma, na concorrência monopolística são encontradas algumas características do mercado competitivo ao mesmo tempo em que se verifica limitado poder de mercado quanto à precificação dos bens e serviços negociados.

Além do tipo de estrutura de mercado dentro do qual se examina se há abuso no aumento de preços, a análise realizada também deve considerar a elasticidade-preço da demanda e a elasticidade-preço da oferta dos produtos envolvidos. A elasticidade é instrumento utilizado pelos economistas para tentar medir a resposta dos compradores e produtores/vendedores às alterações nas condições do mercado (especialmente o preço), possibilitando a análise da oferta e da demanda com maior precisão.

Por meio da estimativa da elasticidade-preço da demanda procura-se mensurar o quanto a quantidade demandada responde às variações no preço. A demanda de um bem é considerada elástica se pequenos aumentos de preço ocasionam grande retração na quantidade demandada (a quantidade demandada responde substancialmente às variações no preço). Por outro lado, diz-se que a demanda de um bem é considerada inelástica se a quantidade demandada pouco responde às variações no preço, isto é, as alterações no preço não provocam mudanças substanciais na quantidade demandada.

No caso de medicamentos, por exemplo, a elasticidade é baixa, pois há pouca alteração da demanda como resposta ao aumento do preço. Em virtude da essencialidade do bem, a maioria das pessoas considera os medicamentos prioritários e, assim, continua a consumi-los, mesmo quando seu preço aumenta. Ainda, não há racionalidade econômica no aumento da dosagem de um medicamento pelo simples fato de estar mais barata sua aquisição.

Por outro lado, bens supérfluos são facilmente descartados no caso do aumento de seu preço, o que se reflete em uma demanda mais elástica. Com efeito, a disponibilidade de produtos similares atua no sentido de tornar a demanda mais elástica, haja vista a possibilidade de substituição do produto. 
A elasticidade da demanda depende, também, do aspecto temporal sob exame, pois os bens tendem a ter uma demanda mais elástica em horizontes de tempo mais longos. No longo prazo há mais facilidade para os consumidores se ajustarem, procurando bens substitutos.

Por sua vez, a elasticidade-preço da oferta procura medir o quanto a quantidade ofertada reage às alterações de preço. Considera-se que a oferta de um bem é elástica se a quantidade ofertada se altera substancialmente em razão da variação nos preços. Por sua vez, diz-se que a oferta de um bem é inelástica se a quantidade ofertada reage pouco à variação nos preços.

A elasticidade-preço da oferta depende da possibilidade de os vendedores alterarem a quantidade do bem que produzem. Se a oferta de um bem pode ser ampliada para atender a oportunidade criada pelos preços mais altos, significa que a oferta é elástica. Por outro lado, a oferta é inelástica se não for possível aumentá-la em decorrência de um aumento de preços.

Na maioria dos mercados, o período considerado também é determinante-chave da elasticidade da oferta. Em geral, a oferta é mais elástica no longo prazo do que no curto prazo, pois, em regra, as empresas não podem alterar com facilidade a dimensão de suas instalações para produzir mais ou menos de um bem em curto espaço de tempo. A seu turno, no longo prazo, a quantidade ofertada pode se alterar substancialmente em resposta às variações no preço.

Nessa trilha, percebe-se que a regulação de preços, quando cabível, deve levar em consideração as características e estrutura do mercado específico e bem assim as especificidades dos bens e serviços sob exame (elasticidade-preço da demanda e a elasticidade-preço da oferta dos produtos envolvidos). Isto porque, inexistindo as chamadas falhas de mercado, como o poder de mercado, externalidades negativas ou distribuição assimétrica de informação (PINHEIRO; SADDI, 2005, p. 258), não há justificativa econômica para a regulação coercitiva, especialmente o controle prévio de preços.

Pelo exposto, conclui-se que não basta a análise jurídica, por meio da ponderação dos princípios da defesa do consumidor e o da livre iniciativa na hipótese de aumentos de preços quando em "situações anormais", como foi o caso do arroz e outros alimentícios básicos, ocorridos no segundo semestre de 2020. É necessário, também, examinar as características dos bens envolvidos, a situação fática de toda a cadeia de produção e o mercado específico à luz da realidade econômica e da concorrência, tendo em vista de se resguardar a sustentabilidade da política regulatória.

Intervenções regulatórias não técnicas elevam sobremaneira o risco de haver excesso de debanda e, por conseguinte, desabastecimento, a formação de filas e ampliação do mercado ilegal, tendo em vista possível ruptura do sistema de troca de informações subjacente ao regime de precificação pelo próprio mercado.

Estas são as lições de Friedrich Hayek (1945, s/n), que, já em 1945, em seu livro "The Use of Knowledge in Society", afirmava: "We must look at the price system as such a mechanism for communicating information if we want to understand its real function-a function which, of course, it fulfils less perfectly as prices grow more rigid". Portanto, apesar da possibilidade jurídica, em razão de interesse público subjacente ou em "situações anormais", o controle de preços privados é tarefa de elevado grau de complexidade, pois requer a conciliação de diversos interesses envolvidos, não apenas dos consumidores, cujos direitos devem ser preservados, havendo, no entanto, limites à atuação estatal. Isso porque, somente diante do caso concreto, e a partir de análise econômica específica dos bens e serviços e tipo de mercado (concorrência perfeita, monopólio, oligopólio, concorrência monopolística, etc.) e de toda a cadeia produtiva, é possível delinear os contornos dos 
aludidos "preços abusivos", o "aumento arbitrário dos lucros" e a elevação de preços "sem justa causa", todos conceitos jurídicos indeterminados.

Nesse contexto, logo após o início dos efeitos da pandemia no Brasil, foi apresentado, na Câmara de Deputados, em 25.03.2020, o Projeto de Lei n. 101008/2020, o qual dispõe sobre "o controle do Estado no combate à manipulação e ao abuso de preços em casos de decretação de Pandemia ou Estado de Calamidade Pública" (CÂMARA DOS DEPUTADOS, 2021). Somente um ano após a apresentação do Projeto de Lei, em 25.03.2021, foi nomeado o relator da matéria, e, no dia seguinte, conferido "prazo para Emendas ao Projeto (5 sessões a partir de 29/03/2021)" Segundo a proposta, há três critérios a serem considerados para a intervenção do Estado na fixação dos preços:

1) o controle de preços se aplicará apenas durante o lapso temporal caracterizado como pandemia ou estado de calamidade pública, eis que se trata de medida temporária e excepcional.

2) a especificação dos itens considerados essenciais ao enfrentamento da pandemia ou da calamidade pública se dará por ato do Ministro da Saúde; III.

3) para fins de controle dos preços será levado em conta o valor médio de mercado com base nos 90 dias que antecederam a decretação da pandemia ou do estado de calamidade pública.

Considerando todos os desafios econômicos e jurídicos já apontados, e tendo em vista a inexistência de lei para disciplinar os termos e limites da intervenção estatal sobre os preços privados, especificamente no contexto da pandemia, por meio da Nota Técnica n. ${ }^{\circ}$ 8/2020/CGEMM/DPDC/SENACON/MJ, de 24.03.2020, ou seja, um dia antes da apresentação do citado Projeto de Lei n. 101008/2020 na Câmara de Deputados, o Ministério da Justiça, com a participação da Secretaria de Advocacia da Concorrência e Competitividade (Seae) e da Secretaria Especial de Produtividade, Emprego e Competitividade (Sepec), ambas do Ministério da Economia, indicou que a avaliação de possível abusividade dos aumentos de preços em situações de excepcional vulnerabilidade, como a do Covid-19, pelos órgãos de defesa do consumidor, deve ser realizada em 5 passos, e caso a caso, pois depende das características do mercado (BRASIL, 2020):

1. Identificar o produto que se quer verificar abusividade (álcool gel, por exemplo);

2. Identificar as empresas que atuam concorrencialmente nesse mercado;

3. Identificar a cadeia produtiva, incluindo a matéria-prima do produto;

4. Solicitar notas fiscais de compra e de venda com uma série histórica confiável, sendo recomendável ao menos uma série de 03 meses (90 dias);

5. Identificar se há racionalidade econômica no aumento de preços ou se ele deriva pura e simplesmente de oportunismo do empresário (...).

Apesar dessa sintonia institucional inicial entre o Ministério da Justiça e o Ministério da Economia, quando a pandemia da Covid-19 começava no pais, em razão do substancial aumento do preço do arroz, já em setembro de 2020, a imprensa noticiou que "após o presidente da República" "pedir lucro 'próximo de zero' aos donos de supermercados, a Secretaria Nacional do Consumidor (Senacon), ligada ao Ministério da Justiça, notificou", "empresas e associações cooperativas ligadas à produção, distribuição e venda de alimentos da cesta básica para questionar a alta nos preços dos produtos". A forte contrariedade do Ministério da Economia com a ação fiscalizadora foi amplamente noticiada pela mídia, o que 
certamente prejudica a construção de uma reputação institucional sólida das ações regulatórias (Carpenter, 2010).

Nesse sentido, sob o ponto de vista da governança, a falta de coordenação intergovernamental, explicitada publicamente no caso em apreço, suscita, também por este aspecto, indagação quanto ao melhor desenho institucional para delimitação do escopo de atividades complexas que são interligadas e possuem natureza interdisciplinar. Constata-se, assim, que as ações estatais em defesa do consumidor devem ser realizadas com cuidado e à luz da realidade econômica, isto é, das forças do mercado que impactam a oferta e demanda de bens e serviços, não sendo possível, no atual estágio de desenvolvimento da economia digital, segmentar de forma absoluta o tema da questão consumerista, concorrencial e da proteção de dados, ainda que possuam distinções em seus objetivos.

Ainda, importante ressaltar o inevitável trade-off entre os distintos modelos possíveis de governança, sendo necessário ter em mente que o órgão ao qual é atribuída determinada função prediz qual é a preponderância dos inevitáveis sopesamentos a serem realizados, tendo em vista inexistir organização neutra, razão pela qual decisions about where to place certain responsibilities are simultaneously decisions about who will resolve certain disputes, and, in turn, what the outcome is likely to be (AMY, 2020, p. 67).

Saliente-se que a coordenação entre as diversas funções e responsabilidades, como a defesa do consumidor, da concorrência e da proteção de dados, não será alcançada pela simples fusão das atividades em apenas um órgão ou instituição, tema que foge ao escopo deste ensaio.

Por fim, importante destacar que no julgamento da citada ADI 6445, o plenário do Supremo Tribunal Federal (STF), em sessão virtual concluída em 28.05.2021, por maioria de votos, decidiu no sentido da inconstitucionalidade a Lei estadual 9.065/2020 do estado do Pará, que obrigava a concessão de desconto mínimo de $30 \%$ nas mensalidades das escolas da educação infantil e ensinos fundamental, médio e superior da rede privada durante o período da a pandemia. Segundo o Ministro Dias Toffoli, que abriu a divergência, a norma paraense não disciplina proteção ao consumidor contra potenciais abusos dos prestadores de serviços educacionais particulares, "mas de uma interferência na essência do contrato, de forma a suspender a vigência de cláusulas que se inserem no âmbito da normalidade dos negócios jurídicos onerosos”. Os Ministros Alexandre de Moraes e Roberto Barroso julgaram procedente o pedido, declarando a inconstitucionalidade formal da norma paraense.

O ministro Marco Aurélio, relator, e o ministros Edson Fachin e Rosa Weber, vencidos, julgaram improcedente a ação direta. Em seu voto, o relator observou que a lei estadual apenas buscou "potencializar, no âmbito regional, mecanismo de tutela da dignidade dos consumidores, ou destinatários finais", nos termos do Código de Defesa do Consumidor, em momento de crise sanitária.

Constata-se, dessa forma, forte indicativo de alteração do entendimento da maioria da Corte Suprema, a qual, conforme já salientado, se posicionava tradicionalmente no sentido da constitucionalidade do controle estatal e limites de preços por razões de interesse público, consideradas legitimadoras da intervenção regulatória na economia.

\section{CONSIDERAÇÕES FINAIS}

O objetivo deste artigo, a partir do contexto iniciado pela pandemia da Covid-19, em 2020, e cujas consequências se agravaram em 2021, consistiu em discutir a juridicidade dos diferentes instrumentos regulatórios disponíveis para o controle de preços no Brasil e a 
dificuldade de conciliação dos diferentes interesses envolvidos, além de apontar alguns problemas específicos relacionados à governança do tema no país.

Longe de esgotar a problematização do tema em foco, o estudo revelou a intercambialidade entre a atuação direta do Estado na economia e a sua atuação indireta, tanto pela regulação, como pelo fomento, sendo possível controlar preços privados por meio da compra de estoque regulador. Também se constatou a existência de diferentes correntes e posicionamentos do Supremo Tribunal Federal, no tocante à questão da regulação de preços privados no Brasil após 1988, havendo indicativo de alteração do entendimento majoritário da Corte quanto à possibilidade de controle estatal de preços privados de escolas particulares.

Ainda, a pesquisa trouxe a lume a percepção de que a análise jurídica, per se, seria insuficiente para o exame da adequação e proporcionalidade da ação estatal, por meio dos instrumentos regulatórios disponíveis (tabelamento, congelamento e controle acompanhamento e limitação), tendo em vista que os preços são reflexos da interação da demanda e oferta em mercados com características variadas. É possível encontrar desde de um mercado constituído por apenas um produtor ou ofertante (monopólio), um mercado oligopolizado (alguns poucos ofertantes) ou mesmo aqueles com características próximas à concorrência perfeita, além da concorrência monopolística, que congrega, simultaneamente, características do monopólio e de concorrência perfeita.

Considerando a necessidade de se examinar, concomitantemente, a estrutura de mercado e o tipo de bem, visando a realizar estudo criterioso sobre a elasticidade-preço da demanda e da elasticidade-preço da oferta dos produtos envolvidos, verificou-se ser imprescindível apurar, preliminarmente, se há "racionalidade econômica no aumento de preços ou se ele deriva pura e simplesmente de oportunismo do empresário", isto é, antes da adoção de medida restritiva da liberdade privada, sob pena de ruptura do sistema de troca de informações subjacente ao regime de precificação pelo próprio mercado, o que pode ocasionar excesso de demanda, desabastecimento, a formação de filas e ampliação do mercado ilegal.

$\mathrm{O}$ dilema pertinente à estrutura de governança adequada foi tangencialmente apontado, considerando a imbricação da defesa do consumidor com a concorrência e de proteção de dados, sendo necessário maior aprofundamento no estudo do tema.

Por fim, espera-se que no bojo das discussões do Projeto de Lei n. 101008/2020, no âmbito do Congresso Nacional, sejam aprofundadas as análises sobre o tema, que comporta múltiplas perspectivas e enfeixa diversos interesses, em muitas circunstâncias contrapostos, sendo necessário ponderar de forma equilibrada os direitos dos consumidores e as limitações das ações estatais, tendo em vista o objetivo de se assegurar desenvolvimento econômico sustentável.

\section{REFERÊNCIAS}

AGÊNCIA IBGE. Síntese de Indicadores Sociais: em 2019, proporção de pobres cai para $24,7 \%$ e extrema pobreza se mantém em $6,5 \%$ da população. Disponível em https://agenciadenoticias.ibge.gov.br/agencia-sala-de-imprensa/2013-agencia-de-noticias/releases/29431sintese-de-indicadores-sociais-em-2019-proporcao-de-pobres-cai-para-24-7-e-extrema-pobreza-se-mantemem-6-5-da-populacao. Acesso: 20.02.2021.

ARAGÃO, Alexandre Santos de. Fungibilidade da Atuação Direta do Estado na Economia com a Regulação e o Fomento. Revista de Direito Público da Economia, volume 56, Belo Horizonte, Fórum, outubro a dezembro de 2016, p. 14-15. 
AMY B. Zegart, FLAWED BY DESIGN: THE EVOLUTION OF THE CIA, JCS, AND NSC I-II (1999). Apud. KOVACIC, William E., HYMAN, David. A. Competition Agencies with Complex Policy Portfolios: Divide or Conquer? Illinois Program in Law, Behavior and Social Science Paper No. LE12-14, 2013,

BARROSO, Luís Roberto. A ordem econômica constitucional e os limites à atuação estatal no controle de preços. Revista de Direito Administrativo. Out/dez. 2001. 226. p.187-212. Disponível em: http://bibliotecadigital.fgv.br/ojs/index.php/rda/article/view/47240. Acesso em 21.12.2020.

BASTOS, Celso Ribeiro. Comentários à Constituição do Brasil. vol. VII. São Paulo: Ed Saraiva. 1990.

BRASIL. Lei $n^{o}$ 8.078, de 11.09.1990. Código de Defesa do Consumidor. Disponível em http://www.planalto.gov.br/ccivil_03/leis/18078compilado.htm. Acesso em 22 dez. 2020.

BRASIL. Lei $n^{o}$ 12.933, de 26.12.2013. Sistema Brasileiro de Defesa da Concorrência - SBDC. Disponível em http://www.planalto.gov.br/ccivil_03/_ato2011-2014/2011/lei/112529.htm. Acesso em 22 dez. 2020.

BRASIL. Supremo Tribunal Federal. ADI 319, Relator Ministro Moreira Alves, julgamento em 03 de março de 1993. Tribunal Pleno. Disponível em: http://portal.stf.jus.br/processos/detalhe.asp?incidente=1501599. Acesso em: 21.12.2020.

CARPENTER, Daniel. Reputation and Power: organizational image and pharmaceutical regulation at the FDA, Princeton University Press, 2010.

CONVERGÊNCIA DIGITAL. Covid-19 aumentou o uso da internet nas classes $C, D$ e E.

.Disponível

em

https://www.convergenciadigital.com.br/cgi/cgilua.exe/sys/start.htm?UserActiveTemplate=site\&UserA ctiveTemplate $=$ mobile $\% 252$ Csite $\&$ infoid $=54528 \&$ sid $=14$. Acesso; 20.02.2021.

ECONOMIA IG. Inflação dos alimentos é a mais alta desde a criação do Real. Disponível https://economia.ig.com.br/2020-11-05/inflacao-dos-alimentos-e-a-mais-altadesde-a-criacao-do-real-confira.html. Acesso em: 03.04.2021.

MOREIRA NETO, Diogo de Figueiredo. Ordem econômica e desenvolvimento na $\begin{array}{llll}\text { Constituição } & \text { de } & \text { 1988. } & \text { Disponível }\end{array}$ https://pge.rj.gov.br/comum/code/MostrarArquivo.php?C=ODUwNw\%2C\%2C.Acesso em: $12.07,2021$.

PINHEIRO E SADDI. Direito, economia e mercados. Rio de Janeiro: Elsevier, 2005.

SAMPAIO, Patrícia Regina Pinheiro; COSTA, Leonardo de Andrade. O geopricing na era da economia digital: a personalização da oferta em face do código de defesa do consumidor. In, 30 anos do Código de Defesa do Consumidor: conquistas e desafios na atualidade Organização de; Ana Alice de Carli/Carla Appollinario de Castro. Rio de Janeiro: Ágora 21, 2020. 
VASCONCELlOS, M. A.; GARCIA, M. E. Fundamentos de economia. 2. ed. São Paulo: Saraiva, 2006.

WHO. Information about Covid-19. Disponível em https://www.who.int/emergencies/diseases/novel-coronavirus2019? gclid=CjwKCAjwpKCDBhBPEiwAFgBzj3BEvLvOQsPS3pyNxUr_hO1simLS9y5hbn vkkQkd1EvolWHyPU99mRoC3-cQAvD_BwE. Acesso em: 03.04.2021. 